\title{
Physiological responses at the lactate-minimum- intensity with and without prior high-intensity exercise
}

Alessandro Moura Zagatto, Johnny Padulo, Adelino Ramos Sanchez da Silva, Paulo de Tarso Guerrero Müller, Willian Eiji Miyagi \& Claudio Alexandre Gobatto

To cite this article: Alessandro Moura Zagatto, Johnny Padulo, Adelino Ramos Sanchez da Silva, Paulo de Tarso Guerrero Müller, Willian Eiji Miyagi \& Claudio Alexandre Gobatto (2016) Physiological responses at the lactate-minimum-intensity with and without prior high-intensity exercise, Journal of Sports Sciences, 34:21, 2106-2113, DOI: 10.1080/02640414.2016.1151921

To link to this article: https://doi.org/10.1080/02640414.2016.1151921

曲 Published online: 29 Feb 2016.

Submit your article to this journal \lceil

Џlll Article views: 434

View Crossmark data $₫$

Citing articles: 2 View citing articles ¿ð 


\title{
Physiological responses at the lactate-minimum-intensity with and without prior high-intensity exercise
}

\author{
Alessandro Moura Zagatto a, Johnny Padulob, Adelino Ramos Sanchez da Silvac, Paulo de Tarso Guerrero Müller ${ }^{d}$, \\ Willian Eiji Miyagie and Claudio Alexandre Gobatto ${ }^{f}$
}

\begin{abstract}
aDepartment of Physical Education, UNESP - Univ Estadual Paulista, Bauru, SP, Brazil; bUniversity e-Campus, Novedrate, Italy; 'SChool of Physical Education and Sports of Ribeirão Preto, University of São Paulo (USP), Ribeirão Preto, SP, Brazil; dLaboratory of Respiratory Pathophysiology (LAFIR), Federal University of Mato Grosso do Sul (UFMS), Campo Grande, MS, Brazil; eUNESP - Univ Estadual Paulista, Bauru, SP, Brazil, USA; 'School of Applied Sciences, Campinas State University (UNICAMP), Limeira, SP, Brazil
\end{abstract}

\begin{abstract}
This study examined the physiological responses during exercise-to-exhaustion at the lactate-minimumintensity with and without prior high-intensity exercise. Eleven recreationally trained males performed a graded exercise test, a lactate minimum test and two constant-load tests at lactate-minimum-intensity until exhaustion, which were applied with or without prior hyperlactatemia induction (i.e., 30-s Wingate test). The physiological responses were significantly different $(P<0.05)$ between constant-load tests for pulmonary ventilation $\left(\mathrm{V}_{\mathrm{E}}\right)$, blood-lactate-concentration $\left(\left[\mathrm{La}^{-}\right]\right), \mathrm{pH}$, bicarbonate concentration $\left(\left[\mathrm{HCO}_{3}\right]\right)$ and partial pressure of carbon dioxide during the initial minutes. The comparisons within constant-load tests showed steady state behaviour for oxygen uptake and the respiratory exchange ratio, but heart rate and rating of perceived exertion increased significantly during both exercise conditions, while the $\forall_{E}$ increased only during constant-load effort. During effort performed after high-intensity exercise: $\bigvee_{E}$, $\left[\mathrm{La}^{-}\right], \mathrm{pH}$ and $\left[\mathrm{HCO}_{3}\right]$ differed at the start of exercise compared to another condition but were similar at the end $(P>0.05)$. In conclusion, the constant-load exercises performed at lactate-minimum-intensity with or without prior high-intensity exercise did not lead to the steady state of all analysed parameters; however, variables such as $\left[\mathrm{La}^{-}\right], \mathrm{pH}$ and $\left[\mathrm{HCO}_{3}\right]$ - altered at the beginning of effort performed after high-intensity exercise - were reestablished after approximately $30 \mathrm{~min}$ of exercise.
\end{abstract}

ARTICLE HISTORY

Accepted 2 February 2016

KEYWORDS

Exercise physiology; kinetic of lactate; metabolic demand; oxygen uptake; workload

\section{Introduction}

The anaerobic threshold can be defined as the exercise intensity which can be performed for the longest time, without significant changes in blood lactate concentration ([La $]$ ) or other physiological responses (Beneke, 2003). During constant-load exercise at low intensity until the anaerobic threshold, an initial rise in [ $\left.\mathrm{La}^{-}\right]$ followed by a plateau has been shown, while during exercise intensity above the anaerobic threshold, the [ $\left.\mathrm{La}^{-}\right]$increases continually (Beneke, 2003; Beneke \& Von Duvillard, 1996). Therefore, it is assumed that maximal lactate steady state represents the highest metabolic rate at which one can maintain an equilibrium between the $\left[\mathrm{La}^{-}\right]$appearance and clearance (Beneke, 2003; Stegmann \& Kindermann, 1982).

Some studies have described a physiological steady state during continuous exercise at maximal lactate steady state (i.e., anaerobic threshold) for oxygen uptake $\left(\mathrm{VO}_{2}\right)$, pulmonary ventilation $\left(\mathrm{V}_{\mathrm{E}}\right)$, respiratory exchange ratio (RER) and blood lactate concentration ([La-]) (Baron et al., 2003, 2008; Grossl, De Lucas, De Souza, \& Guglielmo, 2012), but variables such as the rating of perceived exertion (RPE), blood $\mathrm{pH}$, body temperature and heart rate $(\mathrm{HR})$ do not maintain a steady state. These findings highlight that constant exercise performed at the anaerobic threshold is unlikely to produce a physiological steady state in variables used for exercise intensity monitoring or linked to fatigue (Buchheit et al., 2010).

However, the excessive exercise trials required to determine the maximal lactate steady state (i.e., several 30-min constantload-exercise bouts) is a substantial limitation, and therefore a single-session test such as the lactate minimal test (Tegtbur, Busse, \& Braumann, 1993) could have a higher practical application. The lactate-minimum-intensity has become accepted as a useful procedure for determining the intensity at which lactate production and removal are balanced (Bacon \& Kern, 1999; Dotan et al., 2011; Knoepfli-Lenzin \& Boutellier, 2011; MacIntosh, Esau, \& Svedahl, 2002), allowing the estimative of endurance capacity and anaerobic fitness (e.g., Wingate test as hyperlactatemia induction method) in a single procedure (Zagatto et al., 2014).

Training sessions and competitions of various sports are composed of continuous and/or intermittent efforts at an intensity above the anaerobic threshold, which result in increases in blood lactate concentration, a drop in pH (i.e., in blood and muscles) and other skeletal muscle alterations that can induce fatigue (Ferguson et al., 2007). Moreover, there is evidence that prior high-intensity exercise can alter the $\mathrm{VO}_{2}$

CONTACT Alessandro Moura Zagatto azagatto@yahoo.com.br @ Department of Physical Education, Universidade Estadual Paulista - UNESP, Av. Eng. Luiz Edmundo Carrijo Coube, 14-01, Vargem Limpa, CEP 17033-360, Bauru, SP, Brazil

Laboratory where the research was conducted: Laboratory of Research in Exercise Physiology, Federal University of Mato Grosso do Sul, Campo Grande, Brazil.

() 2016 Taylor \& Francis 
kinetics of subsequent high-intensity exercise (Ferguson et al., 2007), but there are no findings regarding cardiorespiratory (e.g., $\mathrm{VO}_{2}, \mathrm{~V}_{\mathrm{E}}$ and RER) and metabolic ([ $\left.\mathrm{La}^{-}\right], \mathrm{pH}$, blood bicarbonate concentration and other) responses in exercise until exhaustion at maximal lactate steady state intensity performed after a high-intensity effort.

Considering that the anaerobic threshold corresponds to the highest intensity at which blood lactate appearance and clearance are equilibrated (Beneke, 2003; Beneke \& Von Duvillard, 1996), it would be expected that [ $\left.\mathrm{La}^{-}\right]$would present a steady state response, independent of whether the exercise is started after resting or after prior high-intensity efforts, during constant-load exercise performed lactate-minimum-intensity. In addition, assuming recent and consistent findings that lactate-minimum-intensity underestimates the maximal lactate steady state (Dotan, 2012; Dotan et al., 2011; Jones \& Doust, 1998; Knoepfli-Lenzin \& Boutellier, 2011), a metabolic steady state at lactate-minimum-intensity would be more expected (Baron et al., 2003; Fontana, Boutellier, \& Knöpfli-Lenzin, 2009; Grossl et al., 2012) due to the effort being performed below maximal lactate steady state intensity (Dotan, 2012; Dotan et al., 2011; Jones \& Doust, 1998), independent of initial physiological condition (i.e., exercise started after baseline conditions or after pre-exercise hyperlactatemia). Finally, it is known that physiological fatigue processes induced by high-intensity effort are recovered during exercise performed below, but not above, endurance capacity (i.e., critical power) (Chidnok et al., 2013), strengthening the physiological steady state hypothesis for exercise intensity.

Therefore, the purpose of this study was to measure the physiological responses to exercise-to-exhaustion at the lactate-minimum-intensity performed under two pre-exercise conditions: after a full-rest or after a Wingate anaerobic test intended to induce pre-exercise hyperlactatemia. Our hypothesis was that a physiological steady state during constant exercise performed at lactate-minimum-intensity would not be seen in variables linked to exercise prescription (i.e., [ $\mathrm{La}^{-}$, $\mathrm{VO}_{2}, \mathrm{HR}$ and others) or associated with fatigue (i.e., [ $\left.\mathrm{La}^{-}\right], \mathrm{pH}$ and bicarbonate concentration), mainly when performed after a prior high-intensity effort. In addition, the hyperlactatemia state before constant exercise at lactate-minimum-intensity would probably shorten the time to exhaustion and would affect the response of some variables related to the acid-base balance, such as carbon dioxide production and bicarbonate concentration, but not blood lactate concentrations.

\section{Methods}

\section{Participants}

Eleven healthy men, recreationally trained and experienced in cycling (six cyclists - range of cycling training volume from 300 to $350 \mathrm{~km}$ per week; and five triathletes - range of cycling training volume from 150 to $200 \mathrm{~km}$ per week), volunteered to participate in this study. They were aged $31 \pm 9$ years (mean \pm standard deviation (SD)), were of height $1.77 \pm 0.05 \mathrm{~m}$, weighed $74.7 \pm 8.6 \mathrm{~kg}$, had a body mass index of $23.8 \pm 2.8 \mathrm{~kg} \cdot \mathrm{m}^{-2}$ and had a peak oxygen uptake of $50.7 \pm 7.2 \mathrm{~mL} \cdot \mathrm{kg}^{-1} \cdot \mathrm{min}^{-1}$. The participants were informed of the risks and benefits of the study prior to giving written consent. All participants were instructed to maintain their usual eating habits during the period of the study. In addition, participants refrained from drinking alcohol or caffeine-containing beverages for $24 \mathrm{~h}$ and from eating for $2-3 \mathrm{~h}$ before testing to reduce any interference in the experiment. The study was approved by the Ethics Committee for Human Research of the Federal University of Mato Grosso do Sul and was conducted in accordance with the Declaration of Helsinki and with Ethical Standards in Sport and Exercise Science Research.

\section{Study design}

The participants carried out a graded exercise test to measure maximal aerobic power (MAP) and peak oxygen uptake, a lactate minimum test using the Wingate anaerobic test to induce hyperlactatemia (i.e., blood lactate concentration higher than $\left.8 \mathrm{mmol} \cdot \mathrm{L}^{-1}\right)$, and two constant-load tests at lactate-minimumintensity performed until exhaustion. All tests were performed on an electromagnetically braked cycle ergometer (ER-900, Ergoline, Jaeger, Würzburg, Germany) with workload (power) being independent of cycling cadence (i.e., rpm), except for the Wingate anaerobic test which was performed using a mechanically braked cycle ergometer (Biotec 2100, Cefise, Brazil). The cycling cadence was freely chosen (Padulo, Di Capua, \& Viggiano, 2012) during a prior exercise and was maintained thereafter for all exercises. Before each test, a standardised warm-up lasting $5 \mathrm{~min}$ at $75 \mathrm{~W}$ was performed and the tests were initiated $5 \mathrm{~min}$ after the warm-up. The two constant-load tests were performed at the same exercise intensity (i.e., lactateminimum-intensity), performed under one of two pre-exercise conditions: after a full-rest or after a Wingate anaerobic test performed to induce pre-exercise hyperlactatemia. These two constant-load tests were applied in counterbalanced order.

\section{Procedures}

During all procedures, strong verbal encouragement was given to stimulate maximal effort. All tests were carried out in a climate-controlled laboratory (i.e., temperature and relative humidity were $20.5 \pm 1.5^{\circ} \mathrm{C}$ and $43 \pm 3 \%$, respectively), at the same time of day with an interval of $48-72 \mathrm{~h}$ between each exercise test, to ensure complete recovery and to avoid circadian influences (Ammar et al., 2015).

\section{Graded exercise test}

The graded exercise test consisted of a 75-W initial workload that was increased by $25 \mathrm{~W}$ every minute until exhaustion (Miyagi, Malta, \& Zagatto, 2015; Zagatto et al., 2014). Exhaustion was assumed as either voluntary exhaustion or the inability to maintain the predetermined cadence $\left( \pm 5\right.$ revolutions $\cdot \mathrm{min}^{-1}$ ) despite strong verbal stimuli or by voluntary exhaustion after the inability to maintain the predetermined cadence. The highest exercise power attained during the graded exercise test was considered the MAP and was used to select the workload of the incremental phase of lactate minimum test. If 
exhaustion occurred before the end of a stage, the MAP was determined as proposed by Kuipers, Verstappen, Keizer, Geurten, and Van Kranenburg (1985) (Equation 1). During the graded exercise test, the oxygen uptake $\left(\mathrm{VO}_{2}\right)$ was measured (Cosmed Quark PFT-Ergo, Rome, Italy) and the highest $\left(\mathrm{VO}_{2}\right)$ average during the last $30 \mathrm{sec}$ of graded exercise test exercise was assumed to be the peak oxygen uptake.

$$
\operatorname{MAP}(\mathrm{W})=\mathrm{Pc}+\left(\text { incre } \times \frac{\mathrm{t}}{60}\right)
$$

where, MAP is maximal aerobic power, $P C$ is the exercise intensity of the last complete stage, $t$ is the number of seconds sustained during the incomplete stage and " 60 " is the number of seconds required to complete one step.

\section{Lactate minimum test}

The lactate minimum test consisted of three phases: the first was a hyperlactatemia induction that was applied with a Wingate anaerobic test (i.e., 30-sec maximal exercise with workload at $0.075 \mathrm{kp} \cdot \mathrm{kg}^{-1}$ ) (Green, 1995); the second was 8 min of passive recovery; and the third was an incremental exercise with an initial intensity of $35 \%$ of the MAP obtained in the graded exercise test, which was increased by $5 \%$ of MAP each 3 -min stage until voluntary exhaustion (Zagatto et al., 2014).

Lactate-minimum-intensity was considered the intensity where the lowest lactate value was observed during the test (Tegtbur et al., 1993; Zagatto et al., 2014) using a second order polynomial function fitting blood lactate to power (Zagatto et al., 2014). In the second order polynomial function, fitting the blood lactate versus power output curve for lactate-minimum-intensity determination, the fits were only considered valid with an $a$ value $>0$ (i.e., second order polynomial equation) and determination coefficients $\left(R^{2}\right)$ higher than 0.80 , as suggested by De Araujo, Papoti, Manchado, De Mello, and Gobatto (2007).

\section{Constant-load test to exhaustion}

After lactate-minimum-intensity determination, each athlete performed two constant-load tests to exhaustion at individual lactate-minimum-intensity under one of two pre-exercise conditions: after a full-rest or after a Wingate anaerobic test performed to induce pre-exercise hyperlactatemia. The Wingate anaerobic test consisted of a maximal effort of 30 sec with a load of $0.075 \mathrm{kp} \cdot \mathrm{kg}^{-1}$ (Green, 1995). In both tests, the time to exhaustion was also recorded and exhaustion was considered to be the inability to maintain the preferred cadence $\left( \pm 5\right.$ revolutions $\cdot \mathrm{min}^{-1}$ ) despite strong verbal stimuli or by voluntary exhaustion (i.e., the participant stopped cycling voluntarily).

\section{Physiological and metabolic data collection}

The RPE was measured after each exercise stage during the incremental phase of the lactate minimum test and every 5 min during the two constant-load tests, using the 6-20 Borg scale (Borg, 1982).

During all tests, the oxygen uptake $\left(\mathrm{VO}_{2}\right)$, carbon dioxide production $\left(\mathrm{VCO}_{2}\right)$ and pulmonary ventilation $\left(\mathrm{V}_{\mathrm{E}}\right)$ were measured breath by breath using a metabolic cart (Cosmed Quark PFT-Ergo, Rome, Italy) that was calibrated using an ambient air sample and a high-precision gas mixture $\left(16 \% \mathrm{O}_{2}\right.$ and $5 \% \mathrm{CO}_{2}$, balanced $\mathrm{N}_{2}$, White Martins, Osasco, Brazil). The ventilometer was calibrated pre-exercise and verified post-exercise using a 3-L calibration syringe (Hans-Rudolph, Kansas City, USA) in accordance with the manufacturer's instructions. Following the removal of outliers to exclude discrepant breaths, breath-bybreath $\mathrm{VO}_{2}$ data were interpolated to give 1-sec values and smoothed using rolling 5-sec averages (Origin Pro 8.0, Origin Lab Corporation, Microcal, Massachusetts, USA) to enhance the underlying $\mathrm{VO}_{2}$ response characteristics (Özyener, Rossiter, Ward, \& Whipp, 2001). Heart rate was continuously measured using a heart rate thoracic belt wireless device (Polar, Kempele, Finland) and receiver integrated with the metabolic cart.

Capillary blood samples ( 25 microlitres) were drawn from the ear lobe in all tests to measure blood lactate concentration ([La $]$ ). Blood samples were stored at $-20^{\circ} \mathrm{C}$ in tubes containing 50 microlitres of sodium fluoride (1\%) and later analysed in an electrochemical lactate analyser (Yellow Springs Instruments model 1500 Sport, Ohio, USA) to determine [ $\left.\mathrm{La}^{-}\right]$. The blood samples were collected at 3, 5 and $7 \mathrm{~min}$ after graded exercise test, during recovery, prior to exercise and at 3,5 and $7 \mathrm{~min}$ after hyperlactatemia induction. During the two constant-load tests, the capillary blood samples ( 25 microlitres) were drawn every 5 min, and 3, 5 and 7 min after exhaustion.

During the two constant-load tests, $\mathrm{pH}$, bicarbonate concentration $\left(\left[\mathrm{HCO}_{3}\right]\right)$ and partial pressure of carbon dioxide $\left(\mathrm{PvCO}_{2}\right)$ were measured in the venous blood. Approximately 1 millilitre of blood was drawn at rest and after each 5 min of exercise using a small, flexible venous access catheter (Abocath $^{\circledast} \# 20 \mathrm{~g} ;$ B. Braun Melsungen AG, Melsungen, Germany) attached to a three-way stopcock. The catheter was inserted into the cephalic vein around the wrist. The blood $\left.\mathrm{pH}, \mathrm{HCO}_{3}\right]$ and $\mathrm{PvCO}_{2}$ were analysed immediately in a multi-parameter analyser for blood gas (Cobas b 221, Roche Diagnostics, USA).

The $\left[\mathrm{La}^{-}\right], \mathrm{pH},\left[\mathrm{HCO}_{3}\right], \mathrm{PvCO}_{2}$ and RPE data were analysed every $5 \mathrm{~min}$ and at exhaustion. As the time to exhaustion of each participant during the two constant-load tests can be affected both by individual physical ability and the hyperlactatemia induction, the variables were equalised up until 30 min using the exercise time of the maximal lactate steady state test as the standard (Baron et al., 2003). Therefore, data obtained immediately before, during exercise at 5, 10, 15, 20, 25 and 30 min and at exhaustion were considered for comparison. For $\mathrm{VO}_{2}, \mathrm{~V}_{\mathrm{E}}, \mathrm{RER}$ and $\mathrm{HR}$, the data were expressed and analysed as percentages of time to exhaustion between $20 \%$ and $100 \%$ of time to exhaustion (i.e., $t_{20 \%}, t_{40 \%}, t_{60 \%}, t_{80 \%}$ and $\left.t_{100 \%}\right)$, as adopted by Grossl et al. (2012).

\section{Statistical analysis}

The data are presented as the mean \pm SD with a $95 \%$ confidence interval $(95 \% \mathrm{Cl})$. Data normality was initially verified 
using the Shapiro-Wilk's test allowing the use of parametric statistical analysis. Two-way analysis of variance (ANOVA) (tests $\times$ time) for repeated measures was used to compare the values measured in both the constant-load tests. In addition, Mauchly's Sphericity test was applied to the data when sphericity was assumed to be violated due to a significant $F$ test and the Greehouse-Geisserepsilon correction was used. Where significant $F$ ratios were determined, the means were compared using the "Bonferroni" post hoc test. The level of statistical significance was set at a $P$ value $\leq 0.05$. The effect size (i.e., eta squared; $\eta^{2}$ ) obtained in each statistical analysis was also presented and interpreted as proposed by Hopkins (www.sportsci.org/resource/stats), with $\eta^{2}<0.2$ considered as trivial, small was between 0.2 and 0.5 , moderate was between 0.6 and 1.1, large was between 1.2 and 1.9 and very large was >2.0. To test the association between the time to exhaustion in both conditions, the Pearson product-moment correlation test was used. Statistical analyses were performed using the SPSS version 16.0 software package (SPSS Inc., Chicago, IL, USA).

\section{Results}

\section{Graded exercise test and lactate minimum test}

The peak oxygen uptake $\left(\forall \mathrm{O}_{2 \mathrm{PEAK}}\right), \mathrm{MAP}$, peak values of $\mathrm{HR}$, $\left[\mathrm{La}^{-}\right], \mathrm{RER}$ and RPE obtained during graded exercise test are shown in the Table 1.

The initial intensity of the lactate minimum test in the incremental phase corresponded to $35 \%$ of the MAP and was $118.2 \pm 16.3 \mathrm{~W}(95 \% \mathrm{Cl}=107.2-129.1)$. The lactateminimum-intensity was $195.7 \pm 31.8 \mathrm{~W}(95 \% \mathrm{Cl}=174.4-$ 217.1), the blood lactate concentration at lactate-minimum-intensity was $4.6 \pm 1.1 \mathrm{mmol} \cdot \mathrm{L}^{-1}(95 \% \mathrm{Cl}=3.9-5.3)$ and the determination coefficient $\left(R^{2}\right)$ for second-order polynomial function fitting blood lactate - power was $0.92 \pm 0.05(95 \% \mathrm{Cl}=0.88-0.95)$. All participants attained the criteria used for lactate-minimum-intensity determination ( $a$ value $>0$ and $R^{2}>0.80$ ).

For the Wingate anaerobic test performed before the constant-load test, the values of peak power (absolute and relative to body values), mean power (absolute and relative to body values), fatigue index (FI) and blood lactate concentration are presented in the Table 2.

\section{Constant-load test to exhaustion}

The time to exhaustion obtained during the two constant-load tests were $54.1 \pm 14.6 \mathrm{~min}(95 \% \mathrm{Cl}=44.4-63.9)$ for constantload test performed after a full-rest and $47.6 \pm 18.4 \mathrm{~min}(95 \%$ $\mathrm{Cl}=35.3-60.0)$ for constant-load test performed after Wingate anaerobic test. These times to exhaustions were not significantly different $(P=0.102$ ), had a small effect size (effect size $=0.39)$ and were statistically correlated $(r=0.76$; $P=0.007)$.

The $\forall_{2}, \forall_{E}, R E R$ and $H R$ measured over time during both efforts are presented in the Figure 1 ( $A, B, C$ and $D$, respectively), and these same parameters presented over percentage time are presented in Table 3. The $\mathrm{\vee O}_{2}$ during both conditions was not significantly different $(P=0.59$; $\eta^{2}=0.08$ ). However, the $\mathrm{VO}_{2}$ during the effort performed with prior hyperlactatemia induction significantly decreased after $10 \min \left(P=0.02 ; \eta^{2}=0.45\right)$ and then reached a steady state until exhaustion, while the oxygen uptake during exercise without hyperlactatemia induction remained stable (Figure 1A). The oxygen uptake over percentage time also was not significantly different $(P=0.515)$ and had a trivial effect size $\left(\eta^{2}=0.04\right)$ in the comparison between and within groups (Table 1).

Whereas constant-load effort with prior high-intensity exercise significantly increased RER during exercise $(P=0.018$; $\left.\eta^{2}=0.64\right)$, the exercise without prior high-intensity stimulus condition significantly decreased RER during exercise $(P<0.001$; Figure $1 C)$. However, when both exercise conditions were compared, a significant difference was found only for the values measured $5 \mathrm{~min}$ after the beginning of the protocols $(P=0.013)$. For values of RER over percentage time, a non-significant difference was found $(P=0.145$; $\eta^{2}=0.081$ ) (Table 3).

For $V_{E}$, the values at the beginning of the protocol were higher during exercise with prior high-intensity stimulus compared to another condition $\left(P<0.0001 ; \eta^{2}=0.42\right)$ (Figure 1B). This higher response observed in effort performed after high-intensity exercise remained unchanged until voluntary exhaustion. However, for constant-load effort performed after a full-rest, a significant increase in $\forall_{E}$ was observed from the 10th minute of exercise. Similar results were found in percentage of time (Table 3$)(P<0.0001$; $\eta^{2}=0.32$ ). Similar results were observed for $\mathrm{HR}$ with significantly different values observed at $5 \mathrm{~min}$ and $10 \mathrm{~min}$

Table 1. Values of peak oxygen uptake $\left(\mathrm{VO}_{2 \mathrm{PEAK}}\right), \mathrm{MAP}$, peak values of $\mathrm{HR},\left[\mathrm{La}^{-}\right], \mathrm{RER}$ and RPE obtained during graded exercise test.

\begin{tabular}{|c|c|c|c|c|c|c|}
\hline & $\forall 0_{2 \text { PEAK }}\left(\mathrm{mL} \cdot \mathrm{kg}^{-1} \cdot \mathrm{min}^{-1}\right)$ & $\begin{array}{c}\text { MAP } \\
(W)\end{array}$ & $\begin{array}{c}\mathrm{HR} \\
\text { (bpm) }\end{array}$ & $\begin{array}{c}\text { RPE } \\
\text { (A.U.) }\end{array}$ & RER & $\begin{array}{c}{\left[\mathrm{La}^{-}\right]} \\
\left(\mathrm{mmol} \cdot \mathrm{L}^{-1}\right)\end{array}$ \\
\hline Mean \pm SD & $50.7 \pm 7.2$ & $337.6 \pm 46.6$ & $183.0 \pm 8.3$ & $17.7 \pm 2.5$ & $1.29 \pm 0.08$ & $8.8 \pm 2.7$ \\
\hline $95 \% \mathrm{Cl}$ & $45.8-55.5$ & $306.3-368.9$ & 177.4-188.6 & $16.0-19.4$ & $1.24-1.35$ & $7.0-10.6$ \\
\hline
\end{tabular}

Values as mean \pm SD and $95 \%$ confidence interval $(95 \% \mathrm{Cl})$

Table 2. Values of power, $\mathrm{FI}$ and blood lactate concentration, measured during Wingate anaerobic test.

\begin{tabular}{|c|c|c|c|c|c|c|}
\hline & Peak power (W) & Mean power (W) & Peak power $\left(\mathrm{W} \cdot \mathrm{kg}^{-1}\right)$ & Mean power $\left(\mathrm{W} \cdot \mathrm{kg}^{-1}\right)$ & $\mathrm{FI}(\%)$ & {$\left[\mathrm{La}^{-}\right]\left(\mathrm{mmol} \cdot \mathrm{L}^{-1}\right)$} \\
\hline Mean \pm SD & $909.9 \pm 147.0$ & $695.2 \pm 121.5$ & $12.2 \pm 1.2$ & $9.3 \pm 1.2$ & $45.9 \pm 5.9$ & $9.7 \pm 2.2$ \\
\hline $95 \% \mathrm{Cl}$ & $811.2-1008.6$ & $613.5-776.8$ & $11.3-13.0$ & $8.5-10.1$ & $41.9-49.9$ & $8.3-11.2$ \\
\hline
\end{tabular}

Values as mean \pm SD and $95 \%$ confidence interval $(95 \% \mathrm{Cl})$ for peak power (absolute and relative to body values), mean power (absolute and relative to body values), $\mathrm{Fl}$ and blood lactate concentration ([ $\left.\mathrm{La}^{-}\right]$) measured during Wingate anaerobic test performed before the constant-load test. 

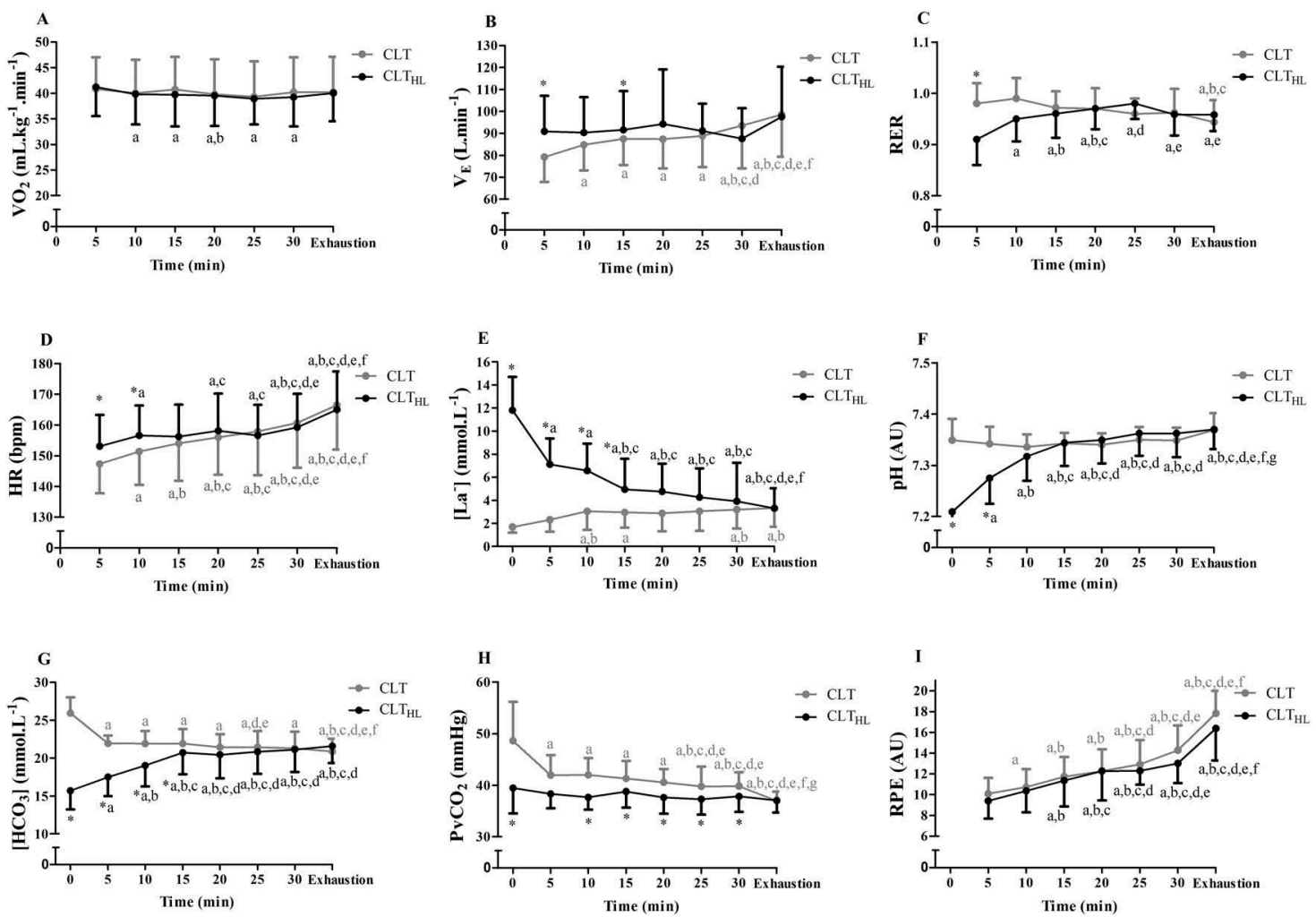

Figure 1. Oxygen uptake $\left(\mathrm{VO}_{2}\right)(1 \mathrm{~A})$, pulmonary ventilation $\left(\mathrm{Z}_{\mathrm{E}}\right)(1 \mathrm{~B})$, respiratory exchange ratio (RER) $(1 \mathrm{C})$ and heart rate (HR) (1D), blood lactate concentration $\left(\left[\mathrm{La}^{-}\right]\right)(1 \mathrm{E}), \mathrm{pH}(1 \mathrm{~F})$, blood bicarbonate $\left(\left[\mathrm{HCO}_{3}\right]\right)(1 \mathrm{G})$, partial pressure of carbon dioxide (PvCO2) $(1 \mathrm{H})$ responses and the rating of perceived exertion (RPE) $(1 \mathrm{II})$ measured during two constant-load tests performed after warm-up (CLT) and hyperlactatemia induction stimuli (CLT $\left.\mathrm{HL}_{\mathrm{L}}\right) .{ }^{*} P<0.05$ from respective time period in another exercise condition. ${ }^{\mathrm{a}} P<0.05$ from 0 min within same exercise; ${ }^{\mathrm{b}} P<0.05$ from 5 min within same exercise; ${ }^{c} p<0.05$ from 10 min within same exercise; ${ }^{\mathrm{d}} p<$ 0.05 from 15 min within same exercise; ${ }^{e} P<0.05$ from 20 min within same exercise; ${ }^{\text {f }} P<0.05$ from 25 min within same exercise; ${ }^{9} P<0.05$ from 30 min within same exercise.

Table 3. Oxygen uptake $\left(\mathrm{VO}_{2}\right)$, pulmonary ventilation $\left(\mathrm{V}_{\mathrm{E}}\right)$, RER and $\mathrm{HR}$ responses measured during percentages of constant-load effort performed with $\mathrm{CLT}_{\mathrm{HL}}$ and without CLT prior high-intensity exercise between $20 \%$ and $100 \%$ of constant-load tests $\left(t_{20 \%}, t_{40 \%}, t_{60 \%}, t_{80 \%}\right.$ and $\left.t_{100 \%}\right)$.

\begin{tabular}{lcccl}
\hline $\begin{array}{l}\text { Time } \\
(\%)\end{array}$ & $\begin{array}{c}\mathrm{VO}_{2}\left(\mathrm{~mL} \cdot \mathrm{kg}^{-1} \cdot\right. \\
\left.\mathrm{min}^{-1}\right)\end{array}$ & $V_{E}\left(\mathrm{~L} \cdot \mathrm{min}^{-1}\right)$ & RER & HR $(\mathrm{bpm})$ \\
\hline $\mathrm{CLT}$ & & & & \\
$t_{20 \%}$ & $39.9 \pm 6.0$ & $83.3 \pm 11.8$ & $0.97 \pm 0.03$ & $151.0 \pm 9.6$ \\
$t_{40 \%}$ & $39.7 \pm 6.4$ & $86.1 \pm 12.9$ & $0.96 \pm 0.04$ & $157.0 \pm 12.5$ \\
$t_{60 \%}$ & $40.1 \pm 6.8$ & $92.9 \pm 14.5^{\mathrm{a}}{ }^{\mathrm{b}}$ & $0.96 \pm 0.04$ & $162.4 \pm 13.1$ \\
$t_{80 \%}$ & $39.2 \pm 6.5$ & $93.7 \pm 17.6^{\mathrm{a}}{ }^{\mathrm{b}}$ & $0.96 \pm 0.04$ & $165.6 \pm 14.4^{\mathrm{a}}{ }^{\mathrm{b}}$ \\
$t_{100 \%}$ & $40.2 \pm 6.9$ & $98.5 \pm 19.0^{\mathrm{a}}{ }^{\mathrm{b}}$ & $0.94 \pm 0.04$ & $166.4 \pm 14.4^{\mathrm{a}}{ }^{\mathrm{b}}$ \\
$\mathrm{CLT}_{\mathrm{HL}}$ & & & & \\
$t_{20 \%}$ & $40.6 \pm 5.3$ & $91.8 \pm 16.8^{*}$ & $0.94 \pm 0.05$ & $155.6 \pm 10.0$ \\
$t_{40 \%}$ & $39.5 \pm 5.9$ & $92.9 \pm 17.7$ & $0.97 \pm 0.03$ & $157.8 \pm 11.3^{\mathrm{a}}$ \\
$t_{60 \%}$ & $39.5 \pm 5.4$ & $94.2 \pm 16.7$ & $0.97 \pm 0.03$ & $158.9 \pm 8.9$ \\
$t_{80 \%}$ & $40.1 \pm 5.0$ & $94.7 \pm 16.2$ & $0.96 \pm 0.04$ & $163.0 \pm 10.0^{\mathrm{a}}{ }^{\mathrm{b}}$ \\
$t_{100 \%}$ & $40.0 \pm 5.5$ & $97.5 \pm 22.8$ & $0.96 \pm 0.03$ & $165.0 \pm 12.4^{\mathrm{a}}{ }^{\mathrm{b}}$ \\
\hline
\end{tabular}

${ }^{\mathrm{a}} P<0.05$ from $t_{20 \%}$ min within same exercise; ${ }^{\mathrm{b}} P<0.05$ from $t_{40 \%}$ min within same exercise; ${ }^{c} P<0.05$ from $t_{60 \%}$ min within same exercise; ${ }^{d} P<0.05$ from $t_{80 \%}$ min within same exercise; ${ }^{*} P<0.05$ from respective time period in another exercise condition.

when comparing both conditions $\left(P<0.001, \eta^{2}=0.80\right)$. However, the comparison within the protocols showed a significant increase in both conditions (Figure 1D). For values over percentage time, the HR increased $(P<0.001)$ and had a moderate effect size $\left(\eta^{2}=0.78\right)$ compared to initial periods in both groups (Table 3), but there were no significant differences between the groups.
[La'] was higher $(P<0.01)$ (Figure $1 \mathrm{E})$, while the $\mathrm{pH}$ (Figure $1 \mathrm{~F}$ ) and blood bicarbonate concentration $\left(\left[\mathrm{HCO}_{3}\right]\right)$ (Figure 1G) were lower $(P<0.001)$ in exercise with prior stimulus compared to exercise without high-intensity stimulus from the start until 15 min into the exercise $\left(\eta^{2}=0.45\right.$, small effect size; $\eta^{2}=0.69$, moderate effect size and $\eta^{2}=0.73$, moderate effect size, respectively). The blood lactate concentrations ([La- $]$ ) at the 10th and 30th minutes were $3.1 \pm 1.6$ and $3.1 \pm 1.9 \mathrm{mmol} \cdot \mathrm{L}^{-1}$, and $6.6 \pm 2.4$ and $3.9 \pm 3.3 \mathrm{mmol} \cdot \mathrm{L}^{-1}$ for the both conditions, respectively. However, the partial pressure of carbon dioxide in the venous blood $\left(\mathrm{PvCO}_{2}\right)$ (Figure $\left.1 \mathrm{H}\right)$ in $\mathrm{CLT}_{\mathrm{HL}}$ was lower than CLT throughout the exercise $\left(P<0.001 ; \eta^{2}=0.43\right.$, small effect size), except during voluntary exhaustion.

As for the comparison within the protocols, the constantload effort performed after a full-rest condition produced an initial and significant increase in $\left[\mathrm{La}^{-}\right]$that reached a steady state after $15 \mathrm{~min}$ of exercise (Figure 1E), without significant alteration in $\mathrm{pH}$ (Figure 1F), and with a significant decrease in $\left[\mathrm{HCO}_{3}\right]$ (Figure $1 \mathrm{G}$ ) and $\mathrm{PvCO}_{2}$ (Figure $1 \mathrm{H}$ ). However, for exercise performed after high-intensity stimulus, the higher $\left[\mathrm{La}^{-}\right]$ after hyperlactatemia induction decreased significantly (Figure 1E), with a significant increase in both pH (Figure 1F) and $\left[\mathrm{HCO}_{3}\right]$ (Figure $1 \mathrm{G}$ ), but without alteration in $\mathrm{PvCO}_{2}$ (Figure $1 \mathrm{H}$ ). A significant increase in values was also observed within the protocols for RPE in both situations $(P<0.001$; $\eta^{2}=0.79$ ), but these values did not differ between the protocols (Figure 11). 


\section{Discussion}

The main findings of the present investigation were that a steady state of $\mathrm{VO}_{2}, \mathrm{RER}, \mathrm{pH}$ and [ $\left.\mathrm{La}^{-}\right]$occurred during constant-load effort performed after a full-rest, and there was an initial unsteady state after the hyperlactatemia induction in constant-load effort performed after high-intensity exercise for $\mathrm{pH},\left[\mathrm{HCO}_{3}\right]$ and $\left[\mathrm{La}^{-}\right]$which was reestablished during exercise. However, the $\mathrm{PvCO}_{2},\left[\mathrm{HCO}_{3}\right], \mathrm{RPE}, \mathrm{HR}$ and $\mathrm{V}_{\mathrm{E}}$ did not reach a steady state during constant-load exercises without prior highintensity exercise, despite the fact that the prior high-intensity exercise (i.e., Wingate anaerobic test) would have some detrimental effects on proximal subsequent exhaustive performance at lactate-minimum-intensity. In fact, a hampered performance at constant-load effort performed after a fullrest would be expected, but the time to exhaustion had a small effect between both conditions, which is likely due to the high variability between tlim outcomes.

Dotan (2012) suggested a reverse lactate threshold test based on decrement-load exercise and reported an $\left[\mathrm{La}^{-}\right]$ increase during the initial loads (i.e., above maximal lactate steady state), an equilibrium at anaerobic threshold intensity and $\left[\mathrm{La}^{-}\right]$only decreasing at an exercise intensity below maximal lactate steady state (i.e., anaerobic threshold). Supposing that lactate-minimum-intensity represents the highest exercise intensity at which blood lactate production and removal are balanced (Bacon \& Kern, 1999; Maclntosh et al., 2002; Tegtbur et al., 1993), an [ $\left.\mathrm{La}^{-}\right]$plateau would be expected after hyperlactatemia induction, albeit at a higher level. However, the [ $\left.\mathrm{La}^{-}\right]$drop over time in constant-load effort performed after high-intensity exercise is due to a higher potential for blood lactate clearance than appearance during effort, reinforcing the findings that lactate-minimum-intensity underestimates the maximal lactate steady state (Dotan, 2012; Dotan et al., 2011; Jones \& Doust, 1998). It is also possible to hypothesise that this decrease in blood lactate concentration after hyperlactatemia induction occurred due to the influence of the $\mathrm{pH}$ value under the lactate/ $\mathrm{H}$ transport (Messonnier, Kristensen, Juel, \& Denis, 2007; Seo, 1984; Thomas et al., 2005), which is due to the increase in monocarboxylate transporter 1 after supra-maximal exercise without an increase in monocarboxylate transporter 4 (Thomas et al., 2005). Several studies have described that lactate shuttles (i.e., monocarboxylate transporters) and the lactate transport direction (i.e., influx or efflux) are activated according to the lactate concentration in the medium (i.e., cells, interstice or blood) (Messonnier et al., 2007; Seo, 1984; Thomas et al., 2005) and therefore, the higher lactate concentration in the blood than in the interstice and cells after hyperlactatemia induction seems to have induced a higher lactate efflux into the cell to be oxidised in the mitochondria.

Nevertheless, the Wingate test performed prior to the constant-load test resulted in a pronounced $\mathrm{pH}$ decrease (Figure 1F) and hyperlactatemia induction (Figure 1E), followed by modifications in the parameters responsible for the acid-base equilibrium such as $\left[\mathrm{HCO}_{3}\right]$ (Figure $1 \mathrm{G}$ ) and $\mathrm{V}_{\mathrm{E}}($ Table 3 and Figure $1 \mathrm{~B}$ ) (Baron et al., 2003; Vanuxem, Delpierre, Fauvelle, Guillot, \& Vanuxem, 1998) and RER (Figure 1C). However, the pronounced modifications of values of $\left[\mathrm{HCO}_{3}\right], \mathrm{V}_{\mathrm{E}}$ and $\left[\mathrm{La}^{-}\right]$after Wingate anaerobic test were attenuated and reestablished following the increase of $\mathrm{pH}$ in relation to the exercise time. These findings are in accordance with the findings of Chidnok et al. (2013), who described that the $\mathrm{pH}$ decrement induced by a high-intensity exhaustive effort would be recovered during exercise performed below but not above endurance capacity (i.e., anaerobic threshold/maximal lactate steady state) and provided evidence of the importance of the endurance capacity in determining the ability to maintain intramuscular homeostasis. In addition, it is plausible to consider that the reestablishment of metabolic and physiological variables can also occur due to the underestimation of maximal lactate steady state by lactate minimum test (Dotan, 2012; Dotan et al., 2011; Jones \& Doust, 1998).

During exercise at anaerobic threshold levels, there is a decrease of stroke volume as a consequence of the increase in body temperature and norepinephrine concentration (Baron et al., 2003, 2008). To maintain constant cardiac output, the HR needs to increase (Baron et al., 2003), which explains why HR increased over time in the present study. Similar results were also reported for maximal lactate steady state intensity during exercise until exhaustion (Baron et al., 2008; Grossl et al., 2012; Mendes et al., 2013). Based on data in the literature regarding continuous exercise at the anaerobic threshold, despite $\mathrm{VO}_{2}$ and [ $\left.\mathrm{La}^{-}\right]$remaining in a steady state during exercise (Baron et al., 2003; Grossl et al., 2012), parameters such as RPE and HR increased continuously during prolonged exercise and should be carefully interpreted because they are widely used for exercise assessment (Meyer, Lucía, Earnest, \& Kindermann, 2005).

To our knowledge, there are few studies that have investigated whether endurance effort represents the intensity corresponding to the maximal physiological steady state and physiological responses at the anaerobic threshold (Baron et al., 2003; Grossl et al., 2012; Mendes et al., 2013). The current study is the first investigation using the lactate minimum test and the first study to measure the physiological response after a high-intensity effort, which improves understanding of the behaviour of physiological variables such as blood lactate during anaerobic threshold (Dotan, 2012).

Therefore, based on the present findings, despite some variables increasing over time such as $H R, V_{E}$ and $R P E$, variables such as $\left[\mathrm{La}^{-}\right], \mathrm{pH}$ and $\left[\mathrm{HCO}_{3}\right]$ were reestablished during the exercise and achieved a steady state after high-intensity effort. The inclusion of the constant-load test performed after high-intensity exercise provided further evidence of the importance of the lactate-minimum-intensity in determining the ability to maintain intramuscular homeostasis, which is likely due to the underestimation of maximal lactate steady state (Dotan, 2012; Jones \& Doust, 1998). In addition, Baron et al. (2008) related that voluntary exhaustion during exercise performed at maximal lactate steady state occurs even when a physiological reserve capacity still exists. Thus, these authors considered voluntary exhaustion during exercise performed at maximal lactate steady state to be associated with an increase in RPE, reinforcing the role of the central governor model in fatigue (Noakes, St Clair Gibson, \& Lambert, 2005). Our findings regarding the steady state of $\mathrm{VO}_{2}$, blood lactate and other parameters, but with an increase in $H R, V_{E}$ and, predominantly, $\mathrm{RPE}$ also reinforced the role of the central governor model in fatigue (Noakes et al., 2005). 
Our findings have relevant practical applications as several coaches and athletes use blood lactate concentration, RPE and HR responses for exercise assessment, including training performed at anaerobic threshold or anchored with respect to this physiological boundary (Meyer et al., 2005). In addition, during training and competition, there are often high-intensity efforts performed, and our findings showed that the metabolic alterations that occurred after intense effort (i.e., $\mathrm{pH},\left[\mathrm{La}^{-}\right]$and $\left[\mathrm{HCO}_{3}\right]$ ) are reestablished over time at lactate-minimum-intensity, achieving physiological stability with values similar to those observed during exercise without hyperlactatemia induction. Therefore, it is necessary to apply caution when using these parameters to assign exercise intensities and mainly to use these parameters for monitoring exercise intensity. In theory, a steady state for HR, RPE and [ $\left.\mathrm{La}^{-}\right]$during constant exercise at the anaerobic threshold is expected. However, our findings showed that the monitoring of training intensity using HR and RPE can lead to an underestimation of exercise intensity, whereas the use of $\left[\mathrm{La}^{-}\right]$can lead to an overestimation of exercise intensity, as [ $\left.\mathrm{La}^{-}\right]$decreased after the high-intensity effort.

A possible limitation of the present study was that the initial intensity of the incremental phase of lactate minimum test corresponded to $35 \%$ of the MAP. Therefore, as the percentage of the anaerobic threshold at peak mechanical power (i.e., MAP) varies according to the training status and population (i.e., $60-90 \%$ of maximal in athletes) (Meyer et al., 2005), it is plausible that some participants started at somewhat different percentages of their respective aerobic power. However, the initial intensity range between participants was tiny and probably did not influence the lactateminimum-intensity assessment. In summary, we can conclude that in constant-load exercise performed at lactateminimum-intensity until exhaustion, the RPE, HR and PvCO2 were strongly altered over time, whereas physiological parameters such as $\mathrm{VO}_{2}$, [La- ], pH and RER remained stable. After high-intensity effort the RPE and HR also increased over time but the initial values of $\left[\mathrm{La}^{-}\right], \mathrm{pH}$ and $\left[\mathrm{HCO}_{3}\right]$ were reestablished during the test and achieved a steady state. These findings reinforce the evidence that lactate-minimum-intensity underestimates the maximal exercise intensity that produces a blood lactate appearance-disappearance equilibrium.

\section{Disclosure statement}

The authors declare no conflicts of interest.

\section{References}

Ammar, A., Chtourou, H., Trabelsi, K., Padulo, J., Turki, M., El Abed, K., ... Hakim, A. (2015). Temporal specificity of training: Intra-day effects on biochemical responses and Olympic-Weightlifting performances. Journal of Sports Sciences, 33(4), 358-368. doi:10.1080/ 02640414.2014.944559

Bacon, L., \& Kern, M. (1999). Evaluating a test protocol for predicting maximum lactate steady state. Journal of Sports Medicine and Physical Fitness, 39(4), 300-308.
Baron, B., Dekerle, J., Robin, S., Neviere, R., Dupont, L., Matran, R., ... Pelayo, P. (2003). Maximal lactate steady state does not correspond to a complete physiological steady state. International Journal of Sports Medicine, 24(8), 582-587. doi:10.1055/s-2003-43264

Baron, B., Noakes, T. D., Dekerle, J., Moullan, F., Robin, S., Matran, R., \& Pelayo, P. (2008). Why does exercise terminate at the maximal lactate steady state intensity? British Journal of Sports Medicine, 42(10), 828833. doi:10.1136/bjsm.2007.040444

Beneke, R. (2003). Methodological aspects of maximal lactate steady stateimplications for performance testing. European Journal of Applied Physiology, 89(1), 95-99. doi:10.1007/s00421-002-0783-1

Beneke, R., \& Von Duvillard, S. P. (1996). Determination of maximal lactate steady state response in selected sports events. Medicine \& Science in Sports \& Exercise, 28(2), 241-246. doi:10.1097/00005768-199602000-00013

Borg, G. A. (1982). Psychophysical bases of perceived exertion. Medicine \& Science in Sports \& Exercise, 14(5), 377-381. doi:10.1249/00005768198205000-00012

Buchheit, M., Chivot, A., Parouty, J., Mercier, D., Al Haddad, H., Laursen, P. B., \& Ahmaidi, S. (2010). Monitoring endurance running performance using cardiac parasympathetic function. European Journal of Applied Physiology, 108(6), 1153-1167. doi:10.1007/s00421-009-1317-x

Chidnok, W., Fulford, J., Bailey, S. J., DiMenna, F. J., Skiba, P. F., Vanhatalo, A., \& Jones, A. M. (2013). Muscle metabolic determinants of exercise tolerance following exhaustion: Relationship to the "critical power". Journal of Applied Physiology, 115(2), 243-250. doi:10.1152/ japplphysiol.00334.2013

De Araujo, G. G., Papoti, M., Manchado, F. B., De Mello, M. A. R., \& Gobatto, C. A. (2007). Protocols for hyperlactatemia induction in the lactate minimum test adapted to swimming rats. Comparative Biochemistry and Physiology Part A: Molecular \& Integrative Physiology, 148(4), 888892. pii: S1095-6433(07)01581-4. doi:10.1016/j.cbpa.2007.09.002

Dotan, R. (2012). Reverse lactate threshold: A novel single-session approach to reliable high-resolution estimation of the anaerobic threshold. International Journal of Sports Physiology and Performance, 7(2), 141-151.

Dotan, R., Zigel, L., Rotstein, A., Greenberg, T., Benyamini, Y., \& Falk, B. (2011). Reliability and validity of the lactate-minimum test. $A$ revisit. The Journal of Sports Medicine and Physical Fitness, 51(1), 42-49.

Ferguson, C., Whipp, B. J., Cathcart, A. J., Rossiter, H. B., Turner, A. P., \& Ward, S. A. (2007). Effects of prior very-heavy intensity exercise on indices of aerobic function and high-intensity exercise tolerance. Journal of Applied Physiology, 103(3), 812-822. pii: 01410.2006. doi:10.1152/japplphysiol.01410.2006

Fontana, P., Boutellier, U., \& Knöpfli-Lenzin, C. (2009). Time to exhaustion at maximal lactate steady state is similar for cycling and running in moderately trained subjects. European Journal of Applied Physiology, 107(2), 187-192. doi:10.1007/s00421-009-1111-9

Green, S. (1995). Measurement of anaerobic work capacities in humans. Sports Medicine, 19(1), 32-42. doi:10.2165/00007256-199519010-00003

Grossl, T., De Lucas, R. D., De Souza, K. M., \& Guglielmo, L. G. A. (2012). Time to exhaustion at intermittent maximal lactate steady state is longer than continuous cycling exercise. Applied Physiology Nutrition and Metabolism, 37(6), 1047-1053. doi:10.1139/H2012-088

Jones, A. M., \& Doust, J. H. (1998). The validity of the lactate minimum test for determination of the maximal lactate steady state. Medicine \& Science in Sports \& Exercise, 30(8), 1304-1313. doi:10.1097/00005768199808000-00020

Knoepfli-Lenzin, C., \& Boutellier, U. (2011). Lactate Minimum Is Valid to Estimate Maximal Lactate Steady State in Moderately and Highly Trained Subjects. Journal of Strength and Conditioning Research, 25(5), 1355-1359. doi:10.1519/Jsc.0b013e3181d6dbf4

Kuipers, H., Verstappen, F. T., Keizer, H. A., Geurten, P., \& Van Kranenburg, G. (1985). Variability of aerobic performance in the laboratory and its physiologic correlates. International Journal of Sports Medicine, 6(4), 197-201. doi:10.1055/s-2008-1025839

MacIntosh, B. R., Esau, S., \& Svedahl, K. (2002). The lactate minimum test for cycling: Estimation of the maximal lactate steady state. Canadian Journal of Applied Physiology, 27(3), 232-249. doi:10.1139/h02-014

Mendes, T. T., Fonseca, T. R., Ramos, G. P., Wilke, C. F., Cabido, C. E. T., De Barros, C. L. M., ... Garcia, E. S. (2013). Six weeks of aerobic training 
improves VO2max and MLSS but does not improve the time to fatigue at the MLSS. European Journal of Applied Physiology, 113(4), 965-973. doi:10.1007/s00421-012-2501-y

Messonnier, L., Kristensen, M., Juel, C., \& Denis, C. (2007). Importance of pH regulation and lactate/ $\mathrm{H}+$ transport capacity for work production during supramaximal exercise in humans. Journal of Applied Physiology, 102(5), 1936-1944. doi:10.1152/japplphysiol.00691.2006

Meyer, T., Lucía, A., Earnest, C. P., \& Kindermann, W. (2005). A conceptual framework for performance diagnosis and training prescription from submaximal gas exchange parameters - theory and application. International Journal of Sports Medicine, 26(Suppl 1), S38-S48. doi:10.1055/s-2004-830514

Miyagi, W. E., Malta, E. D., \& Zagatto, A. M. (2015). Maximal Oxygen Uptake Cannot Be Determined in the Incremental Phase of the Lactate Minimum Test on a Cycle Ergometer. Journal of Sports Science and Medicine, 14(2), 372-378.

Noakes, T. D., St Clair Gibson, A., \& Lambert, E. V. (2005). From catastrophe to complexity: A novel model of integrative central neural regulation of effort and fatigue during exercise in humans: Summary and conclusions. British Journal of Sports Medicine, 39(2), 120-124. doi:10.1136/ bjsm.2003.010330

Özyener, F., Rossiter, H. B., Ward, S. A., \& Whipp, B. J. (2001). Influence of exercise intensity on the on- and off-transient kinetics of pulmonary oxygen uptake in humans. The Journal of Physiology, 533(3), 891-902. doi:10.1111/tjp.2001.533.issue-3
Padulo, J., Di Capua, R., \& Viggiano, D. (2012). Pedaling time variability is increased in dropped riding position. European Journal of Applied Physiology, 112(8), 3161-3165. doi:10.1007/s00421-011-2282-8

Seo, Y. (1984). Effects of extracellular $\mathrm{pH}$ on lactate efflux from frog sartorius muscle. The American Journal of Physiology, 247(3 Pt 1), C175-C181.

Stegmann, H., \& Kindermann, W. (1982). Comparison of prolonged exercise tests at the individual anaerobic threshold and the fixed anaerobic threshold of $4 \mathrm{mmol} \cdot \mathrm{I}^{-1}$ lactate. International Journal of Sports Medicine, 3(2), 105-110. doi:10.1055/s-2008-1026072

Tegtbur, U., Busse, M. W., \& Braumann, K. M. (1993). Estimation of an individual equilibrium between lactate production and catabolism during exercise. Medicine \& Science in Sports \& Exercise, 25(5), 620-627. doi:10.1249/00005768-199305000-00015

Thomas, C., Perrey, S., Lambert, K., Hugon, G., Mornet, D., \& Mercier, J. (2005). Monocarboxylate transporters, blood lactate removal after supramaximal exercise, and fatigue indexes in humans. Journal of Applied Physiology, 98(3), 804-809. doi:10.1152/japplphysiol.01057.2004 Vanuxem, D., Delpierre, S., Fauvelle, E., Guillot, C., \& Vanuxem, P. (1998). Blood ammonia and ventilation at maximal exercise. Archives of Physiology and Biochemistry, 106(4), 290-296. doi:10.1076/ apab.106.4.290.4371

Zagatto, A., Padulo, J., Müller, P., Miyagi, W., Malta, E., \& Papoti, M. (2014). Hyperlactemia induction modes affect the lactate minimum power and physiological responses in cycling. Journal of Strength \& Conditioning Research, 28(10), 2927-2934. doi:10.1519/JSC.0000000000000490 